\title{
Comparative Study of Cardiovascular Response to Laryngoscopy With Endotracheal Intubation and Laryngeal Mask Airway Insertion
}

\section{Hari Poudel $^{1}$, Rabin Sundar Shrestha ${ }^{2}$, S.NBawa ${ }^{1}$}

\section{Authors Affiliations}

${ }^{1}$ Department of Anesthesia, Manipal College of Medical Sciences, Phulbari-11, Pokhara, Nepal.

${ }^{2}$ Department of Anaesthesia, Nobel Medical College Teaching Hospital, Biratnagar, Nepal

\section{Correspondence:}

Dr. Hari Poudel,MD

Department of Anesthesia

Manipal College of Medical Sciences,

Phulbari-11, Pokhara Nepal

Email: haripoude1702@gmail.com

Article received : $20^{\text {th }}$ November, 2019

Article accepted : 30 ${ }^{\text {th }}$ November, 2019

\begin{abstract}
Background: Airwaymanagement is the most essential maneuver during delivery of general anaesthesia. Traditionally, laryngoscopy and endotracheal tube (ETT) insertion has been the mainstay in providing adequate airway management and delivering anaesthesia. The laryngeal mask airway (LMA) offers a much less invasive way of maintaining the airway as it does not pass through the glottis and does not require the use of the laryngoscope. Laryngoscopy and ETT or LMA insertion are noxious stimuli which provoke a transient but marked sympathetic response manifesting as hypertension and tachycardia. Materials and Methods: A hospital based comparative study was conducted to determine the haemodynamic response elicited by laryngoscopy and ETT and compare it with that elicited by LMA in ASA I ( American Society Anesthesiologist) and ASA II patients, undergoing elective surgeries at Manipal Teaching Hospital. Results: The change in hemodynamic parameters after laryngoscopy and ETT insertion were significantly greater than those elicited by LMA $(p<0.0001)$. The increase took about 5 minutes to return to pre insertion values in the ETT group, whereas about 3 minutes in the LMA group. It took a significantly shorter time to insert an LMA $(12.63 \mathrm{sec})$ compared to ETT $(22.76 \mathrm{sec})$. Conclusion: The haemodynamic changes elicited by LMA are less and short lived compared to those elicited by laryngoscopy and ETT insertion. It takes a shorter time and is much easier to insert an LMA compared to ETT. Keywords: Airway; Endotracheal intubation; Laryngoscopy; Laryngeal mask airway
\end{abstract}




\section{INTRODUCTION}

Airway management is the most important procedure during the delivery of general anaesthesia to the patients who are anaesthetized and are unable to maintain an adequate airway on their own and needs the artificial airway maintenance devices. ${ }^{1}$

Traditionally, laryngoscopy and endotracheal intubation has been the mainstay in providing adequate airway management, delivering anaesthesia and avoidance of aspiration. Even though, intubation has many advantages including provision of a reliable airway, prevention of aspiration and delivering of anaesthetic gases, it is not without complications which are mostly observed during insertion, after insertion and during extubation including airway trauma, physiological reflexes like hypoxia, tachycardia, hypertension, malposition, laryngospasm, narrowing and increased airway resistance as well as negative pressure pulmonary edema. ${ }^{1,2}$

The laryngeal mask airway (LMA) offers a much less invasive way of maintaining the airway as it does not pass through the glottis but is placed over the glottis. It does not require use of laryngoscope. It acts as an intermediate between the endotracheal tube and the oropharyngeal airway and offers some of the advantages of the endotracheal tube while surpassing the disadvantages like stimulation of the laryngopharyngeal reflex. ${ }^{2}$

Laryngoscopy and tracheal intubation or LMA insertion are the noxious stimuli which provoke transient but marked sympathetic responses manifesting as hypertension and tachycardia. In susceptible patients particularly those with systemic diseases like hypertension, coronary heart disease, cerebrovascular disease and intracranial aneurysm, even with the transient changes can result in potentially deleterious effects like left ventricular failure, arrhythmias, myocardial ischemia, cerebral hemorrhage and rupture of cerebral aneurysm. ${ }^{3}$

Laryngeal mask airway insertion involves lesser mechanical manipulation of upper airway than endotracheal intubation having its own limitations as is contraindicated in patients who are at risk for aspiration, those with low pulmonary compliance and those with pharyngeal obstruction. ${ }^{1,2}$

Airway management is most essential maneuver during the delivery of safe anesthesia. Several methods can be utilized by the anesthetist to ensure this need is met safely and efficiently. The main method of airway management during delivery of anaesthesia in our setting is by laryngoscopy and endotracheal intubation. LMA, which has recently gained popularity in the world as an airway management tool is not commonly used in our setting. In studies done elsewhere in the world, it has been shown to cause less haemodynamic disturbance as compared to the conventional method of laryngoscopy and endotracheal intubation. It has also been shown to be easier to insert when compared to the endotracheal tube. As it is the role of the anesthetist to ensure safe delivery of anesthesia, the need to seek better ways of improving the quality of care given to our patients while minimizing any undue complications cannot be overemphasized. Therefore for patients with cardiovascular or cerebrovascular pathology, it is important to find a better way of anesthesia delivery for our population so as to avoid the haemodynamic response that is seen with laryngoscopy and endotracheal intubation. In order to improve the quality of care of our patients and decrease morbidity related with the conventional method of endotracheal intubation for anesthesia delivery, this study aims at comparing the haemodynamic responses of laryngoscopy and endotracheal intubation versus laryngeal mask insertion in our population.

With the execution of this study, evidence on the effect of the LMA on the haemodynamic parameters in our population was gathered. This evidence will aid us in developing protocols for improving the quality of the techniques used in delivering anesthetic services to our patients.

\section{MATERIALS AND METHODS}

Following a written and an informed consent, this prospective randomized comparative study was carried out on ASA I and II aged 20-70 years scheduled for elective surgery requiring general Anesthesia with Intermittent positive pressure ventilation either through endotracheal intubation and Laryngeal Mask Airway.

\section{Ethical considerations}


Ethical clearance was sought from the IRC, Manipal College of Medical Sciences. The background, purpose, procedures of the study, measures which were taken to ensure confidentiality of participants, the voluntary nature of the study and applicability of findings were explained. Informed consent was sought from the participants of the study whereby participants were informed on the purpose and importance of the study and were only enrolled into the study if they accepted. Those who declined to participate were given anaesthesia using the standard technique currently used.

\section{Sample size estimation}

Taking prevalence of the case meeting inclusion criteria $=0.33$ with standard error of $15 \%$.

Sample size estimation was done by the calculation with the following formula:

$$
\mathrm{n}=\frac{\mathrm{Z}^{2} * \mathrm{p} * \mathrm{q}}{\mathrm{d}^{2}}
$$

Where $\mathrm{Z}$ is a constant value $=1.96$ or 2

$\mathrm{p}=$ proportion of cases fulfilling inclusion criteria. $=0.88$

$\mathrm{q}=1-\mathrm{p}, 1-0.88=0.12$

$\mathrm{d}=$ allowable error $(15 \%)$

$\mathrm{n}=1.96 * 1.96 * 0.6 * 0.4 /(15 \% \text { of } \mathrm{P})^{2}=40$

\section{Study population:}

Patients were randomly divided into two groups $(\mathrm{n}=40)$

Group E: Laryngoscopy with Endotracheal Intubation

Group L: Laryngeal Mask Airway insertion

\section{Inclusion criteria}

- Patients undergoing elective surgeries

- Aged between 16- 55 years

- Mallampati I and II

- ASA I and ASA II

- Patient willing to participate in the study with written and informed consent

\section{Exclusion Criteria}

- Unwillingness to participate in the study

- History of respiratory problems.
- History of angina, palpitations, syncopal attacks.

- Baseline heart rate $<60$ per minute.

- Baseline systolic pressure $<100 \mathrm{mmHg}$.

- Hepatic, renal problems.

- Regurgitation prone conditions.

- Patients with predetermined difficult airway.

- History of difficult intubation

- Pregnant woman

Assessment of the patients was done during the pre anesthetic evaluation. Exclusion of patients with cardiac and renal problems was based on history and preoperative investigation results. Patients undergoing elective orthopaedic, urological and general surgical procedures of duration between 1-2 hours were selected for the study.

\section{Instruments that were used in the study:}

- Noninvasive BP machine for blood pressure measurement,

- ECG electrodes for ECG monitoring.

- Pulse oximeter probes for measuring oxygen saturation.

- Laryngeal mask airways for airway management in the LMA group.

- Endotracheal tubes (7.0mm-8.5mm) with laryngoscopes for the ETT group.

- Intravenous cannula of $16 \mathrm{G}$ to $20 \mathrm{G}$ (average $18 G)$.

- Drager Fabius anesthetic machines were used for delivery of anesthesia.

- Stop watch was used for measuring the duration of insertion of LMA or intubation.

- Monitoring of Heart rate; Systolic, Diastolic blood pressure; Mean arterial pressure;ECG and Pulse oximetry of the patients was done using Drager infinity Gamma XL monitors.

\section{Anesthesia technique}

The standard anesthesia machine was checked every morning before preceding any procedure.

The patients were cannulated with 16 to $20 \mathrm{G}$ (average 18G) cannula and an infusion of ringer lactate was initiated. ECG, pulse oximeter probe and noninvasive blood pressure cuff were connected 
to the patient. Initial heart rate, blood pressure readings were charted. Subsequently, patients were premedicated with injection Midazolam $0.05 \mathrm{mg} / \mathrm{kg}$, Inj. Fentanyl $1-2 \mathrm{mcg} / \mathrm{kg}$ for analgesia 3 minutes prior to induction along with preoxygenation during these three minutes. Then, induction was done with Inj. I.V. Propofol 2-3 mg/ $\mathrm{kg}$. For both ETT and LMA selected group muscle relaxant for intubation was by the use of injection Succinylcholine $1 \mathrm{mg} / \mathrm{kg}$ body weight. Patients were then ventilated with 100 percent oxygen for 1 minute prior to intubation which was preceded with Macintosh laryngoscope or introducing the laryngeal mask airway. Endotracheal tubes of size $7 / 7.5$ for female and 7/7.5, 8/8.5 for male patients or laryngeal mask size 3/4 for female and size $4 / 5$ for male patients was used depending on body weight. Anesthesia was maintained using oxygen and Isoflurane/ Sevoflurane and Nitrous Oxide. Duration of intubation/insertion was defined as the timing taken from starting of Laryngoscopy/LMA insertion to period of cuff inflation.

Difficulty of intubation was graded I - IV according to the Cormack and Lehane Criteria and insertion conditions of the LMA was graded as excellent (no resistance to insertion), good (slight resistance to insertion), poor (moderate resistance to insertion) or impossible. If insertion becomes impossible the patient was intubated endotracheally. Adequacy of ventilation was monitored clinically by assessing bilateral expansion of chest, auscultating all lung fields anteriorly and on axillary region bilaterally along with epigastric region. Surgical procedures and other manipulations was commenced only after the study was completed i.e. for five minutes after intubation/ insertion.

\section{Monitoring}

Heart rate, Noninvasive blood pressure measurement which includes systolic, diastolic and mean arterial pressure, Oxygen saturation with pulse oximetry and electrocardiography was monitored throughout the study period and were recorded at the following time of procedure:

a) Pre insertion/intubation.

b) Immediately after the laryngoscopy and intubation or insertion of laryngeal mask. c) 1 minute after intubation or insertion of laryngeal mask.

d) 2 minutes after intubation or insertion of laryngeal mask

e) 5 minutes after intubation or insertion of laryngeal mask

\section{Data processing and analysis}

The data collection sheets were checked daily for correctness and consistency. Data collected was coded and entered into the SPSS software. Data was analyzed using SPSS version 20. Analysis between the groups was done using the unpaired sample $t$ test while within group analysis was done using the paired sample $t$ test. Continuous variables were described using mean \pm standard deviation (mean $\pm \mathrm{SD}$ ). $\mathrm{P}$ value of $<0.05$ was measured statistically significant.

\section{RESULTS}

General demographic characteristics of the study groups

The ETT group had 20 males and 20 females and the LMA group had 17 males and 23 females. The ages ranged from 16 to 60 years and 16 to 60 years in the ETT and LMA groups respectively. The range for weight was 45 to $83 \mathrm{~kg}$ and 42 to $68 \mathrm{~kg}$ in the ETT and LMA groups respectively.

\section{Haemodynamic data}

\section{Heart Rate}

Table 1: Mean heart rate at different times among ETT and LMA study participants (Mean \pm SD)

\begin{tabular}{|c|c|c|c|c|}
\hline & $\begin{array}{l}\text { ETT } \\
\text { or } \\
\text { LMA }\end{array}$ & $\mathbf{n}$ & $\begin{array}{l}\text { Mean } \pm \\
\text { Std. } \\
\text { Deviation }\end{array}$ & $\begin{array}{l}\text { Signific- } \\
\text { ance } \\
\text { (P value) }\end{array}$ \\
\hline \multirow{2}{*}{ Preinduction HR } & ETT & 40 & $79.88 \pm 18.311$ & \multirow{2}{*}{.239} \\
\hline & LMA & 40 & $84.43 \pm 15.887$ & \\
\hline \multirow{2}{*}{ Post induction } & ETT & 40 & $83.45 \pm 22.325$ & \multirow{2}{*}{.548} \\
\hline & LMA & 40 & $86.28 \pm 19.482$ & \\
\hline \multirow{2}{*}{$\begin{array}{l}\text { Immediately } \\
\text { Post Insertion } \\
\text { HR }\end{array}$} & ETT & 40 & $91.95 \pm 20.318$ & \multirow{2}{*}{.749} \\
\hline & LMA & 40 & $90.63 \pm 16.347$ & \\
\hline \multirow{2}{*}{$\begin{array}{l}\text { One min after } \\
\text { HR }\end{array}$} & ETT & 40 & $89.00 \pm 17.572$ & \multirow{2}{*}{.383} \\
\hline & LMA & 40 & $85.73 \pm 15.758$ & \\
\hline \multirow{2}{*}{$\begin{array}{l}\text { Three min after } \\
\text { HR }\end{array}$} & ETT & 40 & $85.30 \pm 16.807$ & \multirow{2}{*}{.488} \\
\hline & LMA & 40 & $82.80 \pm 15.232$ & \\
\hline \multirow{2}{*}{$\begin{array}{l}\text { Five min after } \\
\text { HR }\end{array}$} & ETT & 40 & $80.75 \pm 15.622$ & \multirow{2}{*}{.577} \\
\hline & LMA & 40 & $82.90 \pm 18.594$ & \\
\hline
\end{tabular}


ETT - endotracheal tube, LMA - laryngeal mask airway,

Pre insertion values are taken as baseline values.

Table 2: Mean systolic blood pressure at different time points among the study Participants (Mean \pm SD)

\begin{tabular}{|c|c|c|c|c|}
\hline & $\begin{array}{l}\text { ETT } \\
\text { or } \\
\text { LMA }\end{array}$ & $\mathbf{N}$ & $\begin{array}{l}\text { Mean } \pm \\
\text { Std. Deviation }\end{array}$ & $\begin{array}{l}\text { Signific- } \\
\text { ance } \\
\text { (P value) }\end{array}$ \\
\hline \multirow{2}{*}{$\begin{array}{l}\text { Pre induction } \\
\text { SBP }\end{array}$} & ETT & 40 & $132.18 \pm 15.048$ & \multirow{2}{*}{.087} \\
\hline & LMA & 40 & $126.33 \pm 15.187$ & \\
\hline \multirow{2}{*}{$\begin{array}{l}\text { Post induction } \\
\text { SBP }\end{array}$} & ETT & 40 & $117.18 \pm 14.744$ & \multirow{2}{*}{.167} \\
\hline & LMA & 40 & $112.85 \pm 12.949$ & \\
\hline \multirow{2}{*}{$\begin{array}{l}\text { Immediately } \\
\text { Post Insertion } \\
\text { SBP }\end{array}$} & ETT & 40 & $139.30 \pm 19.557$ & \multirow{2}{*}{.000} \\
\hline & LMA & 40 & $123.88 \pm 8.742$ & \\
\hline \multirow{2}{*}{$\begin{array}{l}1 \mathrm{~min} \text { after } \\
\text { SBP }\end{array}$} & ETT & 40 & $126.33 \pm 17.057$ & \multirow{2}{*}{.000} \\
\hline & LMA & 40 & $114.20 \pm 9.879$ & \\
\hline \multirow{2}{*}{$\begin{array}{l}3 \text { min after } \\
\text { SBP }\end{array}$} & ETT & 40 & $114.48 \pm 13.838$ & \multirow{2}{*}{0.26} \\
\hline & LMA & 40 & $108.50 \pm 9.196$ & \\
\hline \multirow{2}{*}{$\begin{array}{l}5 \text { min after } \\
\text { SBP }\end{array}$} & ETT & 40 & $108.73 \pm 13.027$ & \multirow{2}{*}{.440} \\
\hline & LMA & 40 & $106.78 \pm 9.091$ & \\
\hline
\end{tabular}

ETT - endotracheal tube, LMA - laryngeal mask airway,

Pre insertion values are taken as baseline values.

Table 3: Mean diastolic blood pressure at different times among ETT and LMA study participants (Mean \pm SD)

\begin{tabular}{|l|l|l|l|l|}
\hline & $\begin{array}{l}\text { ETT } \\
\text { or } \\
\text { LMA }\end{array}$ & n & $\begin{array}{l}\text { Mean } \pm \\
\text { Std. } \\
\text { Deviation }\end{array}$ & $\begin{array}{l}\text { Signific- } \\
\text { ance } \\
\text { (P value) }\end{array}$ \\
\hline \multirow{2}{*}{ Pre induction } & ETT & 40 & $80.78 \pm 14.257$ & .462 \\
\cline { 2 - 4 } DBP & LMA & 40 & $91.50 \pm 90.648$ & \\
\hline
\end{tabular}

\begin{tabular}{|c|c|c|c|c|}
\hline \multirow{2}{*}{$\begin{array}{l}\text { Post } \\
\text { induction } \\
\text { DBP }\end{array}$} & ETT & 40 & $71.28 \pm 14.664$ & \multirow[t]{2}{*}{.667} \\
\hline & LMA & 40 & $70.00 \pm 11.558$ & \\
\hline \multirow{2}{*}{$\begin{array}{l}\text { Immediately } \\
\text { Post Insertion } \\
\text { DBP }\end{array}$} & ETT & 40 & $88.43 \pm 16.240$ & \multirow[t]{2}{*}{.000} \\
\hline & LMA & 40 & $76.63 \pm 12.534$ & \\
\hline \multirow{2}{*}{$\begin{array}{l}\text { One min after } \\
\text { DBP }\end{array}$} & ETT & 40 & $80.95 \pm 16.077$ & \multirow[t]{2}{*}{.005} \\
\hline & LMA & 40 & $71.63 \pm 12.266$ & \\
\hline \multirow{2}{*}{$\begin{array}{l}\text { Three min } \\
\text { after DBP }\end{array}$} & ETT & 40 & $88.20 \pm 94.542$ & \multirow[t]{2}{*}{.146} \\
\hline & LMA & 40 & $66.10 \pm 11.547$ & \\
\hline \multirow{2}{*}{$\begin{array}{l}\text { Five min after } \\
\text { DBP }\end{array}$} & ETT & 40 & $66.93 \pm 9.880$ & \multirow[t]{2}{*}{.467} \\
\hline & LMA & 40 & $65.13 \pm 12.026$ & \\
\hline
\end{tabular}

ETT - endotracheal tube, LMA - laryngeal mask airway,

Pre insertion values are taken as baseline values.

Table 4: Mean arterial blood pressure at different times among ETT and LMA study participants (mean \pm SD)

\begin{tabular}{|l|l|l|l|l|}
\hline \multirow{2}{*}{} & $\begin{array}{l}\text { ETT } \\
\text { or } \\
\text { LMA }\end{array}$ & $\mathbf{n}$ & $\begin{array}{l}\text { Mean } \pm \\
\text { Std. Deviation }\end{array}$ & $\begin{array}{l}\text { Signific- } \\
\text { ance } \\
\text { (P value) }\end{array}$ \\
\hline \multirow{2}{*}{$\begin{array}{l}\text { Pre Induction } \\
\text { MAP }\end{array}$} & ETT & 40 & $102.63 \pm 18.161$ & \multirow{2}{*}{.111} \\
\cline { 2 - 4 } & LMA & 40 & $94.40 \pm 14.281$ & \\
\hline $\begin{array}{l}\text { Post Induction } \\
\text { MAP }\end{array}$ & ETT & 40 & $90.30 \pm 16.462$ & \multirow{2}{*}{.264} \\
\cline { 2 - 4 } & LMA & 40 & $86.88 \pm 10.021$ & \\
\hline $\begin{array}{l}\text { Immediately } \\
\text { Post Insertion } \\
\text { MAP }\end{array}$ & ETT & 40 & $108.88 \pm 17.572$ & \multirow{2}{*}{.000} \\
\cline { 2 - 4 } & LMA & 40 & $94.73 \pm 10.148$ & \\
\hline $\begin{array}{l}\text { One min after } \\
\text { MAP }\end{array}$ & ETT & 40 & $96.55 \pm 20.645$ & \multirow{2}{*}{.068} \\
\cline { 2 - 4 } & LMA & 40 & $89.73 \pm 10.780$ & \\
\hline $\begin{array}{l}\text { Three min } \\
\text { after MAP }\end{array}$ & ETT & 40 & $88.60 \pm 11.183$ & \multirow{2}{*}{.017} \\
\cline { 1 - 4 } & LMA & 40 & $83.15 \pm 8.580$ & \multirow{2}{*}{.804} \\
\hline \multirow{2}{*}{$\begin{array}{l}\text { Five min after } \\
\text { MAP }\end{array}$} & ETT & 40 & $82.35 \pm 12.249$ & \\
\cline { 2 - 4 } & LMA & 40 & $81.80 \pm 6.726$ & \\
\hline
\end{tabular}

\section{Changes in MAP}

ETT - endotracheal tube, LMA - laryngeal mask airway,

Pre insertion values are taken as baseline values.

\section{DISCUSSION}

This study was conducted on a total of 80 patients, aimed at comparing the haemodynamic changes elicited by laryngoscopy with endotracheal intubation, to those elicited by laryngeal mask 
airway insertion. The two groups, consisting of 40 participants each, were comparable in terms of age, sex, ASA class, and weight and baseline haemodynamic parameters. This study demonstrated that there is a haemodynamic response consisting of an increase in heart rate, SBP, DBP and MAP that occurred with laryngoscopy with ETT insertion as well as with LMA insertion. However, the response caused by laryngoscopy with ETT insertion was significantly greater than that caused by LMA insertion. It was also observed that insertion of an LMA is easier and takes a shorter time compared to laryngoscopy with ETT insertion.

After the induction of anaesthesia, and prior to insertion of any device, the SBP, DBP and MAP in both ETT and LMA groups in this study, showed a decrease from the pre induction values. The heart rates in both the groups showed an increase from the pre induction values. These results were similar to those observed in a study done in Scotland, where it was shown that arterial pressure decreased significantly and heart rate increased significantly after induction of anaesthesia. The same effects were also observed in several other studies done previously. ${ }^{5,6,7}$ This effect could be attributed to the hypotensive effect of the induction drugs used.

The HR, SBP, DBP as well as the MAP were significantly elevated after the insertion of the endotracheal tube in the ETT group of the study compared to the pre intubation values. The elevation persisted for a period of 5 minutes by which the parameters returned to the pre intubation values. These results are similar to those found by Millar and co workers who found that in normotensive patients, laryngoscopy and insertion of a tracheal tube is immediately followed by an average increase in mean arterial pressure of $25 \mathrm{mmHg}$. The study done by Russell and colleagues also demonstrated a significant increase in arterial blood pressure after intubation. The observed changes are probably due to the sympathoadrenal response caused by stimulation of the supraglottic region and that of the trachea.

The LMA group in this study also showed a significant increase in HR, SBP, DBP as well as the MAP after insertion of the LMA. These results are similar to those of a study done to investigate the cardiovascular effects related to insertion of the
Brain laryngeal mask airway compared to those after insertion of a Guedel oral airway, a significant increase in arterial pressure and in heart rate followed insertion of the laryngeal mask and the Guedel airway, with no difference between the two groups at any time. As both the devices did not go through the trachea, such a similarity between the two is expected. This response could be explained by the stimulation of the supraglottic region causing activation of the haemodynamic response reflex.

The changes in haemodynamics in the LMA group were significantly lower compared to those seen with the ETT group. Similar findings were reported by the study done by Anita and colleagues who demonstrated that endotracheal intubation was associated with a significant increase in heart rate and arterial pressure compared to LMA insertion. Several other studies have shown results similar to those of this study. The attenuated response shown by LMA could be due to the fact that the LMA avoids the sympathoadrenal response caused by insertion of the endotracheal tube through the trachea. This explanation is supported by Shinji $\mathrm{T}$ et.al. which showed that direct stimulation by a tracheal tube induces greater cardiovascular responses than stimulation of the glottis by laryngoscopy alone. ${ }^{14}$ In Braude $\mathrm{N}$ et.al. ${ }^{15}$ it was shown that the forces applied during laryngoscopy were only weakly related to the cardiovascular changes, whereas tracheal intubation had a major influence. The results of this study differed from those of Griffin and colleagues who demonstrated that the difference between the LMA and $\underset{15,16}{\text { ETT }}$ groups in haemodynamics was not significant.

SBP and DBP were almost twice as high in the ETT study group compared to the LMA study group after instrumentation. These findings are similar to those of Wilson and colleagues who reported that the cardiovascular responses induced by laryngoscopy and intubation were more than twice as high as those produced by the insertion of an LMA. However, the difference in HR in our study was significantly higher in the ETT group compared to the

LMA group unlike in their study where there was an increase in heart rate in both groups with no significant difference between the groups. The HR 
increase in the ETT group lasted longer in our study similarly to the findings of their study.

The haemodynamic changes in the LMA group took about 3 minutes to return to pre insertion values while it took about 5 minutes for the changes to return to pre intubation values in the ETT group. Several other studies have demonstrated that the haemodynamic response to LMA is short lived compared to that to ETT. ${ }^{4,113}$ The greater and more persistent changes in cardiovascular parameters seen with ETT as compared to LMA insertion probably reflect higher catecholamine levels in the ETT group as seen in previous studies.

The ease of insertion of both the LMA and ETT were also assessed in this study. The majority of the LMA patients (84\%) had excellent insertion conditions while $60 \%$ of the patients in the ETT had Cormack and Lehane grade I corresponding to excellent intubation conditions. The Jamil SN et al. showed that insertion of LMA was easier in 94\% patients while endotracheal intubation was done easily in $53 \%$ of patients only. The LMA being easier to insert as compared to the ETT, could mean that more stimulation is caused while inserting the ETT thus leading to the greater haemodynamic response that we see with the laryngoscopy and ETT intubation.

\section{CONCLUSION}

A significant haemodynamic response consisting of an increase in HR, SBP, DBP and MAP was seen after the insertion of both the LMA and ETT in this study. It was also observed that the haemodynamic response to laryngoscopy and ETT insertion is significantly greater than that to LMA insertion. The response is also short lived in the LMA group compared to ETT group. Time taken to insert an LMA was significantly shorter and insertion was easier as compared to laryngoscopy and ETT insertion. These factors might be contributory to the higher haemodynamic changes seen with laryngoscopy and ETT insertion.

\section{LIMITATIONS OF THE STUDY}

This study was conducted on healthy, normotensive patients with normal airways. It is therefore not known how the changes would have been in hypertensive patients. Patients, who were involved in this study, were all successfully intubated in the first attempt. Perhaps the haemodynamic parameters would show a different picture in patients with difficult intubation. In this study, intermittent recording of the haemodynamics was used, due to the available resources. This could mean that the maximal change could have been missed especially within the first minute of intubation.

\section{REFERENCES}

1. Alan R. Aitkenhead, David J. Rowbotham, Graham Smith. Text book of Anaesthesia. 4th ed. Churchill Livingstone; 2001, 101-6, 423-514.

2. Edward Morgan G. Jr, Maged S. Mikhail, Michael J. Murray. Clinical Anaesthesiology. 4th ed. Lange Medical Books; McGrawn-Hill Medical Publishing Division; 2008, 97-110.

3. Masson AHB. Pulmonary oedema during or after surgery. Anesthesia Analgesia. 1964; 43:440.

4. Wilson IG, Fell D, Robinson SL, Smith G. Cardiovascular responses to insertion of the laryngeal mask. Anaesthesia 1992; 47: 30002.

5. Jamil SN et al. Comparison of LMA and endotracheal intubation in children Indian Journal of Anaesthesia 2009; 53 (2):174-78.

6. Low JM, Harvey JT, Prys-Roberts C, Dagnino J. Studies of anaesthesia in relation to hypertension. VII: Adrenergic responses to laryngoscopy. British Journal of Anaesthesia 1986; 58:471-77.

7. Hickey S, Cameron AE, Asbury AJ. Cardiovascular response to insertion of Brain's laryngeal mask. Anaesthesia 1990; 45: 629-33.

8. Millar Forbes A, Dally FG. Acute hypertension during induction of anaesthesia 
and endotracheal intubation in normotensive man. British Journal of Anaesthesia 1970; 42:618-24,37.

9. Russell WJ, Morris RG, Frewin DB, Drew SE. Changes in plasma catecholamine concentrations during endotracheal intubation. British Journal of Anaesthesia 1981; 53:837-9.

10. Anita N. Shetty, Shinde VS, Chaudhari LJ. A comparative study of various airway devices as regards ease of insertion and haemodynamic responses. Indian Journal of Anaesthesia 2004; 48(2): 134-7.

11. Takashi Asai, Stephen Morris. The laryngeal mask airway: its features, effects and role. Canadian Journal of Anaesthesiology 1994; 41:930-60.

12. Oczenski W, Krenn H, Dahaba AA, et al. Hemodynamic and catecholamine stress responses to insertion of the Combitube ${ }^{\circledR}$, laryngeal mask airway or tracheal intubation. Anesth Analg1999; 88:1389-94.

13. O. Ajuzieogu., A. Amucheazi. \& H. Ezike: Blood Pressure And Heart Rate Responses To Insertion Of The Laryngeal Mask Airway Or Tracheal Intubation. The Internet Journal of Anesthesiology. 2010;27 (2).

14. Shinji T., Taro M., Masayuki M., Hidenori T. Haemodynamic responses to Tracheal Intubation with Laryngoscope Versus Lightwand Intubating device (Trachlight) In Adults with Normal Airway. AnesthAnalg 2002; 95, no 2: 480-84.

15. Braude N, Clements EAF, Hodges UM, Andrews BP. The pressor response and laryngeal mask insertion. A comparison with tracheal intubation. Anaesthesia 1989; 44: 551-4.

16. Griffin RM, Dodd P, Buckoke PC, Tosh GC, Day SJ. Cardiovascular responses to insertion of the brain laryngeal mask. British Journal of Anaesthesia 1989; 63:624-25.
17. Low JM, Harvey JT, Prys-Roberts C, Dagnino J. Studies of anaesthesia in relation to hypertension. VII: Adrenergic responses to laryngoscopy. British Journal of Anaesthesia 1986; 58:471-77.

18. Shribman AJ, Smith G, Achola KJ. Cardiovascular and catecholamine responses ton laryngoscopy with and without tracheal intubation. British Journal of Anaesthesia 1987; 59: 295-99. 